\title{
Sevoflurane inhibits contraction of uterine smooth muscle from pregnant rats similarly to halothane and isoflurane
}

\author{
[Le sévoflurane, pareillement à l'halothane et à l'isoflurane, inbibe la contraction \\ du muscle lisse utérin des rates gravides]
}

Michiaki Yamakage MD PhD, Naoki Tsujiguchi MD, Xiangdong Chen MD, Yasuhiro Kamada MD, Akiyoshi Namiki MD PhD

Purpose: The present study was designed to clarify the direct effects of the volatile anesthetics halothane, isoflurane and sevoflurane on oxytocin-induced uterine smooth muscle contraction from pregnant rats.

Methods: Longitudinal smooth muscle layers were obtained from pregnant rats. Intracellular concentration of free $\mathrm{Ca}^{++}\left(\left[\mathrm{Ca}^{++}\right]_{j}\right)$ was measured, using a fluorescence technique, simultaneously with muscle tension. Inward $\mathrm{Ba}^{++}$current $\left(\mathrm{I}_{\mathrm{Ba}}\right)$ through voltage-dependent $\mathrm{Ca}^{++}$channels (VDCCs) was measured using a whole cell patch clamp technique. After incubation with 20 nM oxytocin, halothane, isoflurane or sevoflurane (1, 2, and 3\%) was introduced into the tissue bath.

Results: All volatile anesthetics significantly inhibited muscle con-

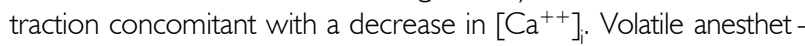
ics also inhibited the peak $I_{\mathrm{Ba}}$. When the anesthetic concentrations were expressed as multiples of minimum alveolar concentrations, there were no differences in the inhibitory potencies of the three volatile agents tested for muscle tension and VDCC.

Conclusions: Volatile anesthetics halothane, isoflurane and sevoflurane reduce the oxytocin-induced contraction of pregnant uterine smooth muscle. Inhibition of the contraction by the volatile anesthetics is due, at least in part, to the decrease in $\left[\mathrm{Ca}^{++}\right]_{i}$, and the decrease in $\left[\mathrm{Ca}^{++}\right]_{i}$ may be mediated by inhibition of VDCC activity.

Objectif : La présente étude voulait préciser les effets directs d'anesthésiques volatils, halothane, isoflurane et sévoflurane, sur la contraction du muscle lisse utérin induite par l'oxytocine chez des rates gravides.
Méthode : Des couches longitudinales de muscle lisse ont été prélevées chez des rates gravides. La concentration intracellulaire de $\mathrm{Ca}^{++}\left(\left[\mathrm{Ca}^{++}\right]_{i}\right)$ libre a été mesurée par une technique fluorescente, simultanément à la tension musculaire. Le courant entrant de $\mathrm{Ba}^{++}\left(E_{B d}\right)$ au travers des canaux calciques potentiel-dépendants $\mathrm{Ca}^{++}$(CCPD) a été mesuré à l'aide d'une technique de "patch clamp" d'une cellule complète. À la suite de l'incubation avec 20 nM d'oxytocine, l'halothane, l'isoflurane ou le sévoflurane ( I, 2 et 3 \%) a été introduit dans le bain tissulaire.

Résultats : Les trois anesthésiques volatils ont inhibé la contraction musculaire de façon significative et concomitante à la baisse de $\left[\mathrm{Ca}^{++}\right]_{i}$. Ils ont aussi inhibé le $E_{\mathrm{Ba}}$ maximal. Les concentrations d'anesthésiques exprimées en multiples des concentrations alvéolaires minimales ne présentaient pas de différence de potentiel inhibiteur pour les trois médicaments testés pour la tension musculaire et les CCPD.

Conclusion : Les anesthésiques volatiles halothane, isoflurane et sévoflurane réduisent la contraction induite par l'oxytocine du muscle lisse de l'utérus gravide. Cette inhibition est causée, en partie du moins, par la baisse de $\left[\mathrm{Ca}^{++}\right]_{i}$, cette baisse de diminution de $\left[\mathrm{Ca}^{++}\right]_{i}$ pouvant être le résultat de l'inhibition de l'activité des CCPD.

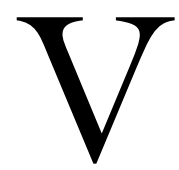

OLATILE anesthetics are often used for general anesthesia in obstetric surgery. ${ }^{1,2}$ While these anesthetics have been shown to induce uterine atonicity followed by hemorrhage during abortion or delivery, ${ }^{3,4}$ the direct mechanisms by which these agents produce muscle

From the Department of Anesthesiology, Sapporo Medical University School of Medicine, Sapporo, Hokkaido, Japan.

Address correspondence to: Dr. Michiaki Yamakage, Department of Anesthesiology, Sapporo Medical University School of Medicine,

South 1, West 16, Chuo-ku, Sapporo, Hokkaido 060-8543, Japan. Phone: 81-11-611-2111 (ext. 3568); Fax: 81-11-631-9683; E-mail: yamakage@sapmed.ac.jp

Supported in part by 1) a grant-in-aid (No. 12671489, 2000) for research from the Ministry of Education, Science, Sports and Culture,

Tokyo, Japan and; 2) an incentive grant (No. III-27, 2000) for research from Uehara Memorial Foundation, Tokyo, Japan.

Accepted for publication August 15, 2001.

Revision accepted September 26, 2001. 
relaxation are not fully known. ${ }^{5,6}$ As in other smooth muscles, intracellular free $\mathrm{Ca}^{++}$is a primary regulator of uterine smooth muscle contraction, ${ }^{7}$ and $\mathrm{Ca}^{++}$ influx through membrane-associated voltage-dependent $\mathrm{Ca}^{++}$channels (VDCCs) is important for the regulation of the concentration $\left(\left[\mathrm{Ca}^{++}\right]_{\mathrm{i}}\right) .8$ The present study was, therefore, designed to clarify the direct effects of the volatile anesthetics halothane, isoflurane and sevoflurane on oxytocin-induced uterine smooth muscle contraction in the pregnant rat by simultaneously measuring the muscle tension and $\left[\mathrm{Ca}^{++}\right]_{\mathrm{i}}$ using a fluorescence technique ${ }^{9,10}$ and by measuring VDCC activity using a patch clamp technique. ${ }^{11,12}$

\section{Methods}

The experimental protocol was approved by the Sapporo Medical University Animal Care and Use Committee. Twenty-four rats (Sprague-Dawley, weighing $200-250 \mathrm{~g}$ ) in the late stage of gestation (19-21 days) were anesthetized, the uteri were excised quickly, and the longitudinal muscle layer of each uterus was isolated.

The muscle tissue was cut into small strips $(2-\mathrm{mm}$ wide and $15-\mathrm{mm}$ long), and the strips were loaded with $5 \mu \mathrm{M}$ acetoxymethyl ester of fura-2, an indicator of $\mathrm{Ca}^{++}$. Each fura-2-loaded muscle strip was held in an organ bath $\left(37^{\circ} \mathrm{C}\right)$, and one end of the muscle strip was connected to a strain gauge transducer. Experiments were performed using a fluorescence spectrometer (CAF-100; Japan Spectroscopic, Tokyo, Japan). Excitation light was passed through 340- and $380-\mathrm{nm}$ rotating filters. The light emitted from the muscle strip at $500 \mathrm{~nm}$ was measured, and the ratio of the fluorescence $\left(\mathrm{R}_{340 / 380}\right)$ was used as an indicator of $\left[\mathrm{Ca}^{++}\right]_{\mathrm{i}}{ }^{9}, 10$ The tissue was contracted with $20 \mathrm{nM}$ oxytocin, a potent contractile agonist. Halothane, isoflurane, or sevoflurane $(1,2$, and $3 \%$, respectively) were randomly introduced into the tissue bath through bubbling in the presence of oxytocin. Volatile anesthetic concentrations in the gas phase during the bubbling were continuously monitored with a calibrated mass spectrometer (ATOM 303; ATOM, Tokyo, Japan). In order to express the quantitative changes in muscle contractility and in $\left[\mathrm{Ca}^{++}\right]_{\mathrm{i}}$, the areas under the contraction and $\left[\mathrm{Ca}^{++}\right]_{i}$ curves were measured for five minutes using Sigma Plot (Jandel Scientific, Corte Madera, CA, USA). ${ }^{13}$

Conventional whole cell patch clamp techniques ${ }^{11,12}$ were used to observe the inward current through VDCCs. Uterine smooth muscle tissues were minced and digested in $\mathrm{Ca}^{++}$-free modified Tyrode's solution to which $0.05 \%$ (w/v) collagenase (Lot\#: 034-10533) had been added. Cells were then dispersed by tritura- tion, filtered by nylon mesh, and centrifuged. The pellet was resuspended in a modified Kraftbrühe solution ${ }^{14}$ and stored at $4^{\circ} \mathrm{C}$ for up to five hours before use. Micropipettes had resistances of 3-5 $\mathrm{M} \Omega$, and the pipette solution contained (in $\mathrm{mM}$ ) $\mathrm{CsCl} 20, \mathrm{CsOH}$ $110, \mathrm{MgCl}_{2} 5.2$, L-glutamate 112, EGTA 10, $\mathrm{Na}_{2}$ ATP 5.0, and HEPES 10, with the $\mathrm{pH}$ adjusted to 7.2 with Tris. The bath solution contained (in $\mathrm{mM}$ ) tetraethylammonium chloride $130, \mathrm{MgCl}_{2} 1.0, \mathrm{BaCl}_{2} 5.0$, glucose 10, and HEPES 10, with the $\mathrm{pH}$ adjusted to 7.35 with Tris. $\mathrm{Ba}^{++}$was used, instead of $\mathrm{Ca}^{++}$, in order to prevent an indirect inhibitory effect of oxytocin on VDCC activity. An aliquot of the cell suspension was placed in a temperature-controlled chamber $\left(37^{\circ} \mathrm{C}\right)$, and the patch membrane was disrupted by strong negative pressure. Membrane currents were monitored using a patch clamp amplifier (CEZ-2400; Nihon Kohden, Tokyo, Japan), and the amplifier output was low-pass-filtered at $2,000 \mathrm{~Hz}$. Inward $\mathrm{Ba}^{++}$currents through VDCCs $\left(\mathrm{I}_{\mathrm{Ba}} \mathrm{s}\right)$ were elicited by $100-\mathrm{msec}$ depolarizing pulses from a holding potential of $-60 \mathrm{mV}$. Leak currents were subtracted, and membrane capacitance and series resistance were compensated. After obtaining a stable baseline of peak $\mathrm{I}_{\mathrm{Ba}}$ with $20 \mathrm{nM}$ oxytocin, cells were then exposed to bath solution equilibrated with one of three volatile anesthetics: halothane, isoflurane or sevoflurane $(1,2$, or $3 \%$, respectively).

The following drugs and chemicals were used: acetoxymethyl ester of fura-2 (Dojindo, Kumamoto, Japan), oxytocin (Sigma Chemical, St. Louis, MO, USA), collagenase (Wako Pure Chemical, Osaka, Japan), halothane (ICI, Dighton, MA, USA), isoflurane (Ohio Medical Products, Madison, WI, USA), and sevoflurane (Maruishi Pharmaceutical, Osaka, Japan).

Data are expressed as means \pm SD. For the measurement of $\left[\mathrm{Ca}^{++}\right]_{i}$ and muscle tension, oxytocininduced changes in $\left[\mathrm{Ca}^{++}\right]_{\mathrm{i}}\left(\mathrm{R}_{340 / 380}\right)$ and muscle tension were used as references. 9,10 Changes in peak $\mathrm{I}_{\mathrm{Ba}}$ with exposure to anesthetics were compared at each applied potential by the paired, two-tailed t test. Other data were analyzed using one-way ANOVA for repeated measurements with Fisher's test. In all comparisons, $P<0.05$ was considered significant.

Results

In resting conditions, oscillatory phasic contractions of the uterine smooth muscle strips with a concomitant oscillatory increase in $\left[\mathrm{Ca}^{++}\right]_{i}$ were observed (Figure 1A). Treatment with $20 \mathrm{nM}$ oxytocin significantly increased oscillatory rates $(3.3 \pm 1.0$ to $4.3 \pm$ 1.2 cycles $\cdot \mathrm{min}^{-1}$ ) by approximately $30 \%$ and elevated the peaks of the contraction by approximately $35 \%$ and of the $\left[\mathrm{Ca}^{++}\right]_{\mathrm{i}}$ by approximately $21 \%$. Nifedipine 


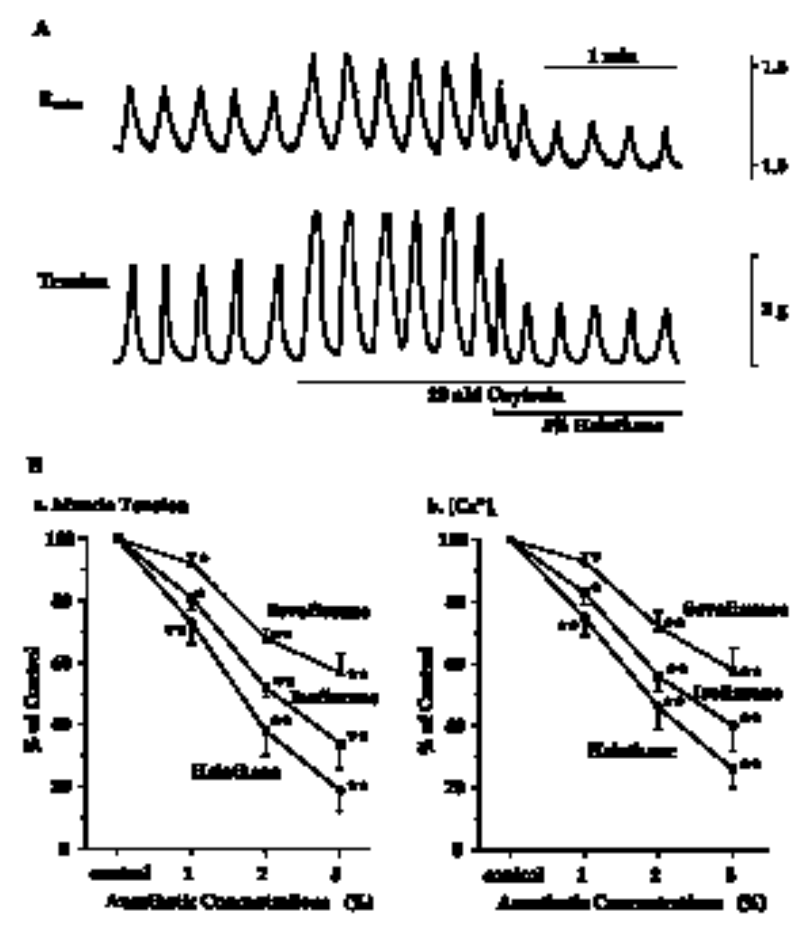

FIGURE 1 Effects of volatile anesthetics on pregnant uterine smooth muscle tension and $\left[\mathrm{Ca}^{++}\right]_{\mathrm{i}}$ (indicated by $\mathrm{R}_{340 / 380}$ ) during contraction caused by $20 \mathrm{nM}$ oxytocin. (A) Halothane (3\%) was introduced in the presence of oxytocin. (B) Relationships of percent responses of contraction and $\left[\mathrm{Ca}^{++}\right]_{i}$ with the concentrations of the volatile anesthetics tested in this study: halothane $(\bullet)$, isoflurane ( ), and sevoflurane ( ). Symbols represent means \pm SD ( $n=6$ at each point). ${ }^{*} P<0.05,{ }^{*} P<0.01 v s$ control without the anesthetic.

( $1 \mu \mathrm{M})$, a potent L-type VDCC antagonist, completely blocked the oscillatory changes both in the muscle contraction and in $\left[\mathrm{Ca}^{++}\right]_{\mathrm{i}}$ (data not shown, $\left.n=3\right)$. As shown in Figure 1A, 3\% halothane inhibited both the muscle contraction and increase in $\left[\mathrm{Ca}^{++}\right]_{\mathrm{i}}$ induced by $20 \mathrm{nM}$ oxytocin. Halothane significantly decreased oscillatory rates by $15 \%$ and suppressed the oxytocininduced peaks of muscle contraction by approximately $67 \%$ and of $\left[\mathrm{Ca}^{++}\right]_{\mathrm{i}}$ by $57 \%$. The other two volatile anesthetics, isoflurane and sevoflurane, showed similar inhibitory effects both on the muscle contraction and on $\left[\mathrm{Ca}^{++}\right]_{\mathrm{i}}$ (data not shown). Figure 1B shows the relationships of percent responses of contraction (a) and $\left[\mathrm{Ca}^{++}\right]_{\mathrm{i}}$ (b) with anesthetic concentrations (\%). Each volatile anesthetic significantly decreased muscle contraction and $\left[\mathrm{Ca}^{+}\right]_{\mathrm{i}}$ in a dose-dependent manner ( $n=6$ each). Based on the percent anesthetic concentrations in the gas phase, the order of inhibitory
$\mathbf{A}$

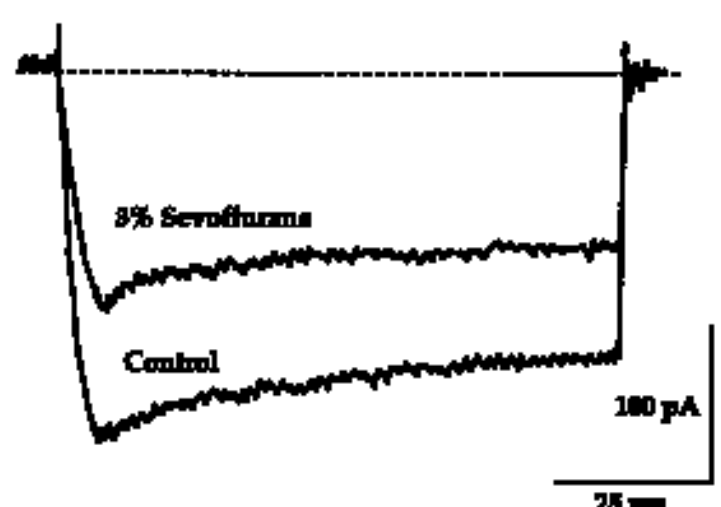

$\mathbf{B}$
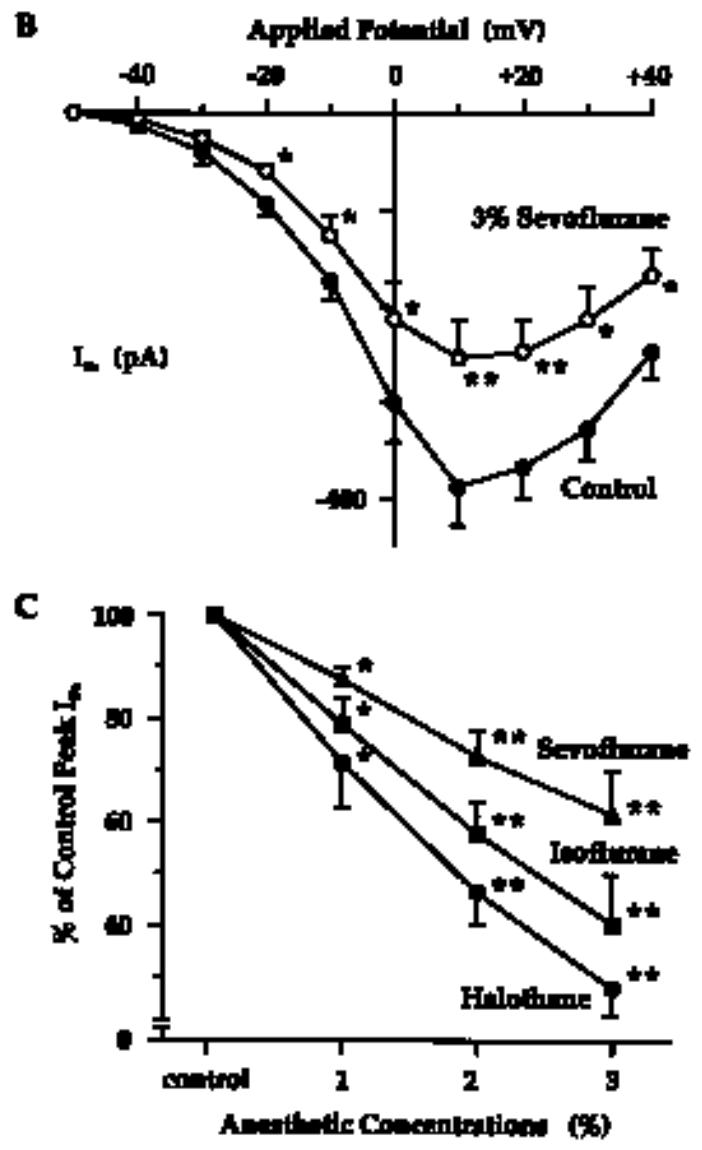

FIGURE 2 Effects of volatile anesthetics on depolarizationinduced whole-cell $\mathrm{Ba}^{++}$currents $\left(\mathrm{I}_{\mathrm{B}_{\mathrm{a}}}\right)$. (A) Typical recordings of $\mathrm{I}_{\mathrm{Ba}}$ induced by pulses as long as $+10 \mathrm{mV}$ with or without $3 \%$ sevoflurane. (B) Relationships between peak $\mathrm{I}_{\mathrm{B}}$ and applied potential before $(\bullet)$ and after exposure to sevoflurane $(\circ)$. (C)

Relationships between peak $\mathrm{I}_{\mathrm{B} \text { a }}$ at $+10 \mathrm{mV}$, expressed as percentage of control, and the concentrations of volatile anesthetics in the gas phase. Symbols represent means $\pm \mathrm{SD}$ ( $n=6$ at each point). ${ }^{*} P$ $<0.05,{ }^{*} P<0.01$ vs control without the anesthetic. 
potencies for both the muscle tension and $\left[\mathrm{Ca}^{++}\right]_{\mathrm{i}}$ was halothane $>$ isoflurane $>$ sevoflurane.

The $\mathrm{I}_{\mathrm{Ba}}$ seen in dispersed rat uterine smooth muscle cells peaked at approximately $10-15 \mathrm{msec}$ and was inactivated slowly with a time constant of approximately $300-500 \mathrm{msec}$ (Figure 2A: control). In baseline conditions, threshold activation of $\mathrm{I}_{\mathrm{Ba}}$ occurred at approximately $-40 \mathrm{mV}$, and maximum peak current amplitude was obtained at approximately $+10 \mathrm{mV}$ (Figure 2B). In 12 cells, the maximum peak $\mathrm{I}_{\mathrm{Ba}}$ was $-389 \pm 89$ pA. Nifedipine $(1 \mu \mathrm{M})$ completely inhibited the currents (data not shown, $n=3$ ). As shown in a representative trace for depolarization from -60 to $+10 \mathrm{mV}$ (Figure 2A: sevoflurane), $3 \%$ sevoflurane inhibited the magnitude of $\mathrm{I}_{\mathrm{Ba}}$ but did not obviously alter the time course of the current. Sevoflurane significantly inhibited $\mathrm{I}_{\mathrm{Ba}}$ at step potentials ranging from $-20 \mathrm{mV}$ to $+40 \mathrm{mV}$ and decreased peak $\mathrm{I}_{\mathrm{Ba}}$ by approximately $33 \%$ (Figure 2B). There was no apparent shift in the voltage dependence of $\mathrm{I}_{\mathrm{Ba}}$ with sevoflurane. The other two volatile anesthetics showed similar inhibitory effects on $\mathrm{I}_{\mathrm{Ba}}$ (data not shown). Figure $2 \mathrm{C}$ shows the relationships between the percentage of control peak $\mathrm{I}_{\mathrm{Ba}}$ at $+10 \mathrm{mV}$ and the \% anesthetic concentrations of volatile anesthetics in the gas phase. All three volatile anesthetics significantly inhibited the peak $\mathrm{I}_{\mathrm{Ba}}$ in a dose-dependent manner, and the order of inhibitory potencies for $\mathrm{I}_{\mathrm{Ba}}$ was halothane $>$ isoflurane $>$ sevoflurane.

\section{Discussion}

The present study showed that the volatile anesthetics tested significantly inhibited agonist-induced pregnant uterine smooth muscle contraction, at least in part, by decreasing $\left[\mathrm{Ca}^{++}\right]_{\mathrm{i}}$. This result for muscle tension is consistent with those obtained by Naftalin et al. ${ }^{15}$ and by Munson et al. ${ }^{16}$ using rat and human uterine smooth muscles, respectively. This result is also in agreement with the general observations in airway ${ }^{10,17}$ and in vascular ${ }^{18}$ smooth muscles. Inositol $1,4,5-$ triphosphate $\left(\mathrm{IP}_{3}\right)$-induced $\mathrm{Ca}^{++}$release from intracellular $\mathrm{Ca}^{++}$stores, especially the sarcoplasmic reticulum, and $\mathrm{Ca}^{++}$influx through VDCCs are both important for the oxytocin-induced uterine smooth muscle contraction during delivery. ${ }^{8,13}$ Phillippe et al. ${ }^{8,13,19}$ demonstrated that activation of the $\mathrm{IP}_{3}$-signaling pathway results in the development of intracellular $\mathrm{Ca}^{++}$oscillation phenomena. $\mathrm{Ca}^{++}$influx through VDCCs is also essential for the maintenance of repetitive contractions, ${ }^{7,13}$ because the blockade of $\mathrm{Ca}^{++}$ influx through VDCCs by nifedipine completely blocked the oscillatory contractions in this study. Therefore, the mechanisms by which volatile anesthetics decreased $\left[\mathrm{Ca}^{++}\right]_{\mathrm{i}}$ are thought to be, at least in part, due to an inhibition of VDCC activity.

Using a whole-cell patch clamp technique, we measured depolarization-induced $\mathrm{I}_{\mathrm{Ba}}$ in rat uterine smooth muscle cells. Based on their time and voltage dependencies and their sensitivity to blockade by nifedipine, these currents are presumed to reflect the activity of Ltype VDCCs. ${ }^{20,21}$ Volatile anesthetics significantly inhibited $\mathrm{I}_{\mathrm{Ba}}$ through L-type VDCCs of the uterine smooth muscle cells without an apparent change in the kinetics of activation and inactivation (Figure 2). Volatile anesthetics did not alter the voltage dependence of $\mathrm{I}_{\mathrm{Ba}}$, suggesting that these anesthetics have no effect on membrane surface charge or on the voltage sensor of the channel. These data indicate one of the cellular effects of volatile anesthetics that can account for the uterine smooth muscle relaxant effects of the anesthetics. ${ }^{15,16}$

We did not investigate other second messengers such as $\mathrm{IP}_{3}$ and cyclic AMP. $\mathrm{IP}_{3}$ can release $\mathrm{Ca}^{++}$from the sarcoplasmic reticulum and also activates VDCCs directly. ${ }^{13}$ Since it was reported that halothane inhibits the agonist-induced increase in $\mathrm{IP}_{3}$ concentration in canine tracheal smooth muscle, ${ }^{22}$ it is possible that the anesthetic also decreases $\mathrm{IP}_{3}$ concentration in uterine smooth muscle. Furthermore, Yang et al. ${ }^{6}$ reported that halothane increases intracellular concentration of cyclic AMP in rat uterine smooth muscle. An increase in cyclic AMP concentration can decrease $\left[\mathrm{Ca}^{++}\right]_{\mathrm{i}}$, leading to uterine smooth muscle relaxation. Further studies are, therefore, needed to clarify the relative importance of the inhibitory effect of the volatile anesthetics on VDCC activity.

We did not measure the exact concentrations of the volatile anesthetics in the bathing chamber and showed our data using percent anesthetic concentrations in the gas phase, because the systems (both fluorescence and patch-clamp techniques) used in this study were the same as those we had used in our previous studies. ${ }^{10,17,23}$ Minimum alveolar concentrations (MACs) of the volatile anesthetics halothane, isoflurane and sevoflurane in adult rats are $1.03 \%,{ }^{24} 1.46 \%{ }^{24}$ and $2.68 \%,{ }^{2}$ respectively. Although the effect of pregnancy on the MAC of sevoflurane has not been reported in rats, it has been shown that the MACs of halothane and isoflurane are not affected by either sex or pregnancy. ${ }^{24}$ When the anesthetic concentrations were expressed as MACs, differences in inhibitory potencies of the volatile anesthetics tested for muscle tension, $\left[\mathrm{Ca}^{++}\right]_{\mathrm{i}}$ or VDCC activity became indistinguishable. Therefore, the three volatile anesthetics tested in this in vitro study appear to be equivalent for general anesthesia in obstetric surgery, as far as uterine contraction is concerned and in as much as our in vitro results apply to the clinical situation. 
In conclusion, the volatile anesthetics halothane, isoflurane and sevoflurane at clinically relevant concentrations $(1-3 \%)$ significantly reduce the oxytocin-induced contraction of isolated preparations of uterine smooth muscle obtained from pregnant rats. Inhibition of the contraction by the volatile anesthetics is due, at least in part, to the decrease in $\left[\mathrm{Ca}^{++}\right]_{i}$, and the decrease in $\left[\mathrm{Ca}^{++}\right]_{\mathrm{i}}$ may be mediated by inhibition of VDCC activity.

\section{References}

1 Zagorzycki MT. General anesthesia in cesarean section: effect on mother and neonate. Obstet Gynecol Surv 1984; 39: 134-7.

2 Baraka A, Siddik S, Assaf B. Halothane for supplementation of general anesthesia during cesarean section (Letter). Can J Anesth 1999; 46: 95-6.

3 Milligan KR. Use of halogenated anesthesia with maternal hemorrhage. NAACOGS Clin Issu Perinat Womens Health Nurs 1991; 2: 396-401.

4 Gilstrap III LC, Hauth JC, Hankins GDV, Patterson $A R$. Effect of type of anesthesia on blood loss at cesarean section. Obstet Gynecol 1987; 69: 328-32.

5 Laszlo A, Buljubasic N, Zsolnai B, Kampine JP, Bosnjak $Z J$. Interactive effects of volatile anesthetics, verapamil, and ryanodine on contractility and calcium homeostasis of isolated pregnant rat myometrium. Am J Obstet Gynecol 1992; 167: 804-10.

6 Yang JC, Triner L, Vulliemoz $\Upsilon$, Verosky M, Ngai SH. Effects of halothane on the cyclic 3',5'-adenosine monophosphate (cyclic AMP) system in rat uterine muscle. Anesthesiology 1973; 38: 244-59.

7 Wray $S$. Uterine contraction and physiological mechanisms of modulation. Am J Physiol 1993; 264: Cl-18.

8 Phillippe M, Chien EK. Intracellular signaling and phasic myometrial contractions. J Soc Gynecol Invest 1998; 5: 169-77.

9 Ozaki H, Kwon S-C, Tajimi M, Karaki H Changes in cytosolic $\mathrm{Ca}^{2+}$ and contraction induced by various stimulants and relaxants in canine tracheal smooth muscle. Pflügers Arch 1990; 416: 351-9.

10 Yamakage M. Direct inhibitory mechanisms of halothane on canine tracheal smooth muscle contraction. Anesthesiology 1992; 77: 546-53.

11 Hamill OP, Marty A, Neher E, Sakmann B, Sigworth FJ. Improved patch-clamp techniques for high- resolution current recording from cells and cell-free membrane patches. Pflügers Arch 1981; 391: 85-100.

12 Yamakage M, Hirshman CA, Croxton TL. Volatile anesthetics inhibit voltage-dependent $\mathrm{Ca}^{2}+$ channels in porcine tracheal smooth muscle cells. Am J Physiol 1995; 268: L187-91.

13 Phillippe M. Mechanisms underlying phasic contractions of pregnant rat myometrium stimulated with alminum fluoride. Am J Obstet Gynecol 1994; 170: 981-90.

14 Isennberg G, Klockner U. Calcium tolerant ventricular myocytes prepared by preincubation in a "KB medium”. Pflügers Arch 1982; 395: 6-18.

15 Naftalin NJ, Phear WPC, Goldberg AH. Halothane and calcium interaction in isolated pregnant and postpartum rat myometrium. Anesthesiology 1976; 45: 31-8.

16 Munson ES, Embro WJ. Enflurane, isoflurane, and halothane and isolated human uterine muscle. Anesthesiology 1977; 46: 11-4.

17 Yamakage M, Kohro S, Kawamata T, Namiki A Inhibitory effects of four inhaled anesthetics on canine tracheal smooth muscle contraction and intracellular $\mathrm{Ca}^{2+}$ concentration. Anesth Analg 1993; 77: 67-72.

18 Tsuchida H, Namba H, Yamakage M, Fujita S, Notsuki $E$, Namiki A. Effects of halothane and isoflurane on cytosolic ion concentrations and contraction in the vascular smooth muscle of the rat aorta. Anesthesiology 1993; 78: 531-40.

19 Phillippe M, Basa A (+)cis-Dioxolane stimulation of cytosolic calcium oscillations and phasic contractions of myometrial smooth muscle. Biochem Biophys Res Commun 1997; 231: 722-5.

20 Young RC, Smith LH, McLaren MD. T-type and L-type calcium currents in freshly dispersed human uterine smooth muscle cells. Am J Obstet Gynecol 1993; 169: 785-92.

21 Obya $\Upsilon$, Sperelakis $N$. Tocolytic agents act on calcium channel current in single smooth muscle cells of pregnant rat uterus. J Pharmacol Exp Ther 1990; 253: $580-5$.

22 Yamakage M, Kohro S, Matsuzaki T, Tsuchida H, Namiki A. Role of intracellular $\mathrm{Ca}^{2+}$ stores in the inhibitory effect of halothane on airway smooth muscle contraction. Anesthesiology 1998; 89: 165-73.

23 Yamakage M, Tsujiguchi N, Hattori J-I, Kamada $\Upsilon$, Namiki A. Low-temperature modification of the inhibitory effects of volatile anesthetics on airway smooth muscle contraction in dogs. Anesthesiology 2000; 93: 179-88.

24 Mazze RI, Rice SA, Baden JM. Halothane, isoflurane, and enflurane MAC in pregnant and nonpregnant female and male mice and rats. Anesthesiology 1985; 62: 339-41.

25 Kashimoto S, Furuya A, Nonaka A, Oguchi T, Koshimizu M, Kumazawa T. The minimum alveolar concentration of sevoflurane in rats. Eur J Anaesthesiol 1997; 14: 359-61. 